\title{
МОРФОЛОГО-АНАТОМИЧЕСКОЕ ИЗУЧЕНИЕ ТРАВЫ ВЯЗЕЛЯ РАЗНОЦВЕТНОГО (CORONILLA VARIA L.)
}

\author{
(С) Дроздова И.Л., Калуцкий И.А.
}

\section{Кафедра фармакогнозии и ботаники Курского государственного медицинского университета, Курск E-mail: irina-drozdova@yandex.ru}

Род Вязель (Coronilla L.) семейства Бобовые (Fabaceae) насчитывает 55 видов, распространенных в Европе, Африке и Азии. В России произрастает 1 вид - вязель разноцветный (Coronilla varia L.). Возможность использования нового вида сырья в научной медицине делает необходимым изучение морфологических признаков и анатомического строения различных органов надземной части вязеля разноцветного (стебель, лист, чашелистик, лепесток венчика) и выявление его характерных диагностических признаков. В результате проведенных исследований установлены морфологоанатомические признаки сырья, которые позволяют идентифицировать траву вязеля разноцветного и могут быть использованы при разработке нормативной документации.

Ключевые слова: вязель разноцветный, морфологические и анатомические признаки, идентификация растительного сырья.

\section{MORPHOLOGICAL AND ANATOMIC RESEARCH OF CORONILLA VARIA L. Drozdova I.L., Kalutsky I.A.}

Department of Pharmacognosy and Botany of Kursk State Medical University, Kursk

Coronilla genus of Fabaceae family has 55 species, distributed in Europe, Africa and Asia. In Russia there grows 1 species - Coronilla varia L. The ability to use a new type of raw material in scientific medicine makes it necessary to investigate the morphological features and anatomic structure of various organs of the aboveground parts of Coronilla varia (stem, leaf, petal, and sepal) and to detect its characteristic diagnostic signs. The results of the investigation fulfilled found the morphological and anatomical signs of raw materials which identify the herb of Coronilla varia L., and can be used in the developing regulatory documentation.

Keywords: Coronilla varia L., morphological and anatomic features, raw material identification.

Род Вязель (Coronilla L.) семейства Бобовые (Fabaceae) насчитывает 55 видов, распространенных в основном в умеренно теплых и субтропических районах Европы, Африки и Западной Азии. Во флоре России произрастает один вид вязель разноцветный (в. пестрый) (Coronilla varia L.). Данный вид представляет собой многолетнее травянистое растение высотой 30-100 см с ползучим ветвистым корневищем и многочисленными полыми ветвистыми стелющимися или восходящими побегами. Цветет с июня до конца лета. Вязель разноцветный встречается во многих районах Европейской части России, Западной Сибири, на Кавказе, в Крыму; в Средней России широко распространен в черноземной полосе. Растет на суходольных или пойменных лугах, в луговых степях, в светлых лесах, на опушках и полянах, на открытых травянистых склонах, среди кустарников. Растение быстро разрастается, может образовывать обширные заросли, поэтому имеет значительную сырьевую базу $[8,10,12]$.

Представители семейства бобовые содержат различные группы БАВ, широко используются в научной и народной медицине, многие виды являются фармакопейными $[1,4,5,6]$. В настоящее время вязель разноцветный применяется только в народной медицине при заболеваниях сердечно-сосудистой системы, туберкулезе легких, как кардиотоническое, диуретическое, гемостатическое средство; проявляет антибактериальную активность [12]. В научной медицине препараты вязеля не применяются, тем не менее растение содержит комплекс БАВ (сердечные гликозиды, кумарины, флавоноиды, дубильные вещества, витамины и другие), поэтому его следует считать перспективным в лекарственном отношении.

Возможность внедрения травы вязеля разноцветного в официнальную медицину делает необходимым проведение морфолого-анатомических исследований с целью выявления признаков, которые могут быть использованы при диагностике лекарственного растительного сырья.

Цель работы - проведение морфолого-анатомического анализа травы вязеля разноцветного (Coronilla varia L.) и выявление диагностических признаков лекарственного растительного сырья.

\section{МАТЕРИАЛЫ И МЕТОДЫ ИССЛЕДОВАНИЯ}

Объектом исследования служила трава вязеля разноцветного, собранная в 2016 г. в Курской области в период массового цветения растений. 
Исследования проводили на свежем, фиксированном (в смеси спирт этиловый 96\% вода очищенная - глицерин (1:1:1)) и высушенном растительном материале $[2,3,7$, 9, 11]. Препараты для выявления анатомодиагностических признаков готовили согласно общим фармакопейным статьям Государственной фармакопеи Российской Федерации XIII издания: ОФС.1.5.1.0002.15 «Травы» и ОФС.1.5.3.0003.15 «Техника микроскопического и микрохимического исследования лекарственного растительного сырья и лекарственных растительных препаратов» [4]. Микропрепараты изучали с помощью микроскопа «Биолам». Микрофотографии выполняли с помощью цифровой насадки и редактировали с использованием программы «Adobe Photoshop 7.0».

\section{РЕЗУЛЬТАТЫ ИССЛЕДОВАНИЯ И ИХ ОБСУЖДЕНИЕ}

Морфологическое исследование. При макроскопическом анализе были выявлены морфологические признаки травы вязеля разноцветного. Установлено, что лекарственное сырье представляет собой цельные или частично измельченные олиственные стебли длиной до $30 \mathrm{~cm}$ с цветками, а также кусочки стеблей, листьев, цветков. Стебли полые, ребристые, вверху обычно ветвистые. Листья длиной до 15 см, непарноперистосложные, с 5-15 парами листочков овальной или продолговатой формы, заканчивающихся короткой колючкой, с короткими черешочками, имеют очередное расположение. Прилистники ланцетно-линейные или продолговатые, длиной до 3 мм. Цветки собраны в 12-20-цветковые пазушные полушаровидные зонтиковидные соцветия с короткими цветоножками, сидящие на длинных (до 15 см) цветоносах. Цветки мотылькового типа длиной до 1 см. Чашечка колокольчатая, с острыми треугольными зубцами, состоит из 5 чашелистиков длиной до 2 мм. Венчик розовый, белый или фиолетовый; лепестки в 5 раз длиннее чашечки; флаг и лодочка нередко пестро окрашены, с темными полосками или пятнами. Тычинок 10 (9 сросшихся и 1 свободная). Пестик один, с верхней одногнездной завязью. Цвет листьев, стеблей зеленый или серовато-зеленый, цветков белый, розовый или фиолетовый.

Анатомическое исследование. При микроскопическом анализе были выявлены анатомические признаки травы вязеля разноцветного.

Стебель. На поперечном срезе стебель полый, ребристый, имеет вторичное строение. Покровная ткань представлена однослойным эпидермисом. Первичная кора хорошо развита, состоит из уголковой колленхимы, паренхимы первичной коры и эндодермы. В центральном цилиндре проводящая система представлена открытыми биколлатеральными пучками, расположенными по кругу. В центральной части стебля находятся рыхло расположенные тонкостенные клетки паренхимы сердцевины округлой формы, среди которых встречаются клетки с оранжево-коричневым содержимым; в самом центре стебель полый (рис. 1).

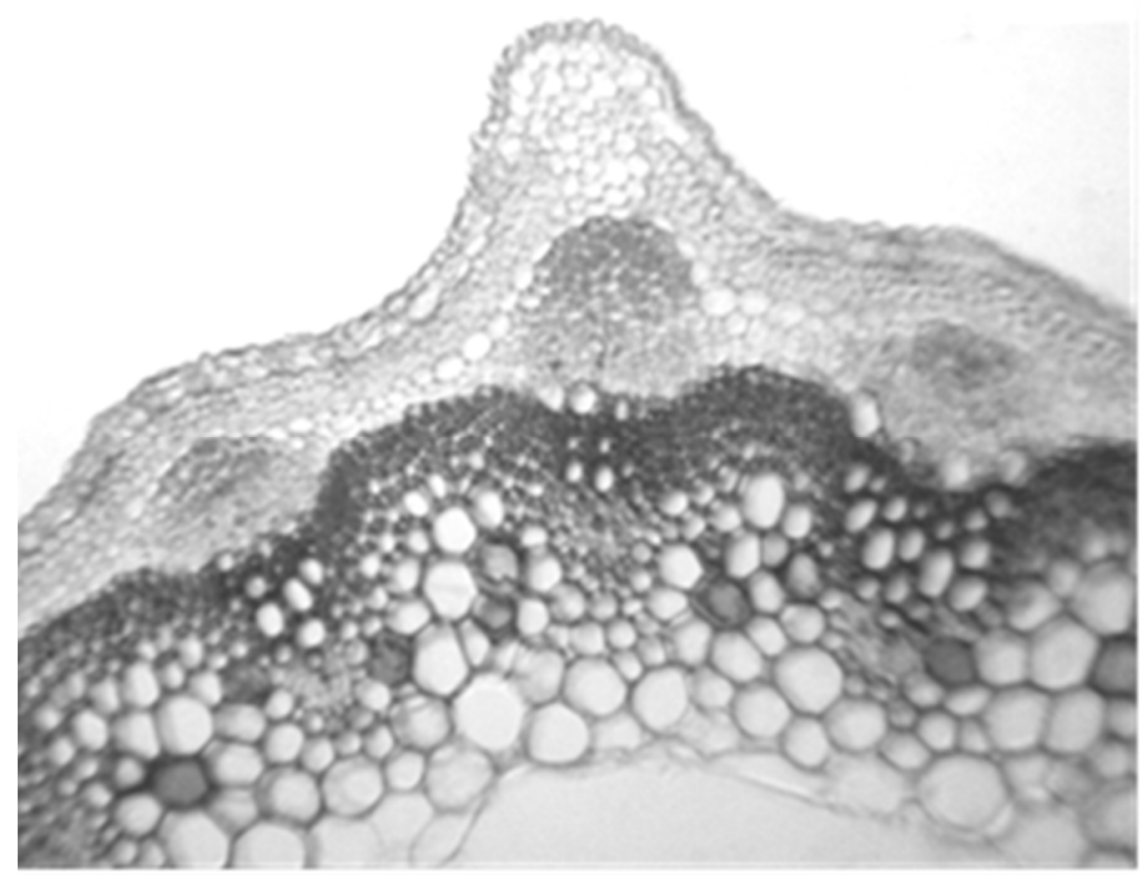

Рис. 1. Фрагмент поперечного среза стебля (Ув. 10×8). 

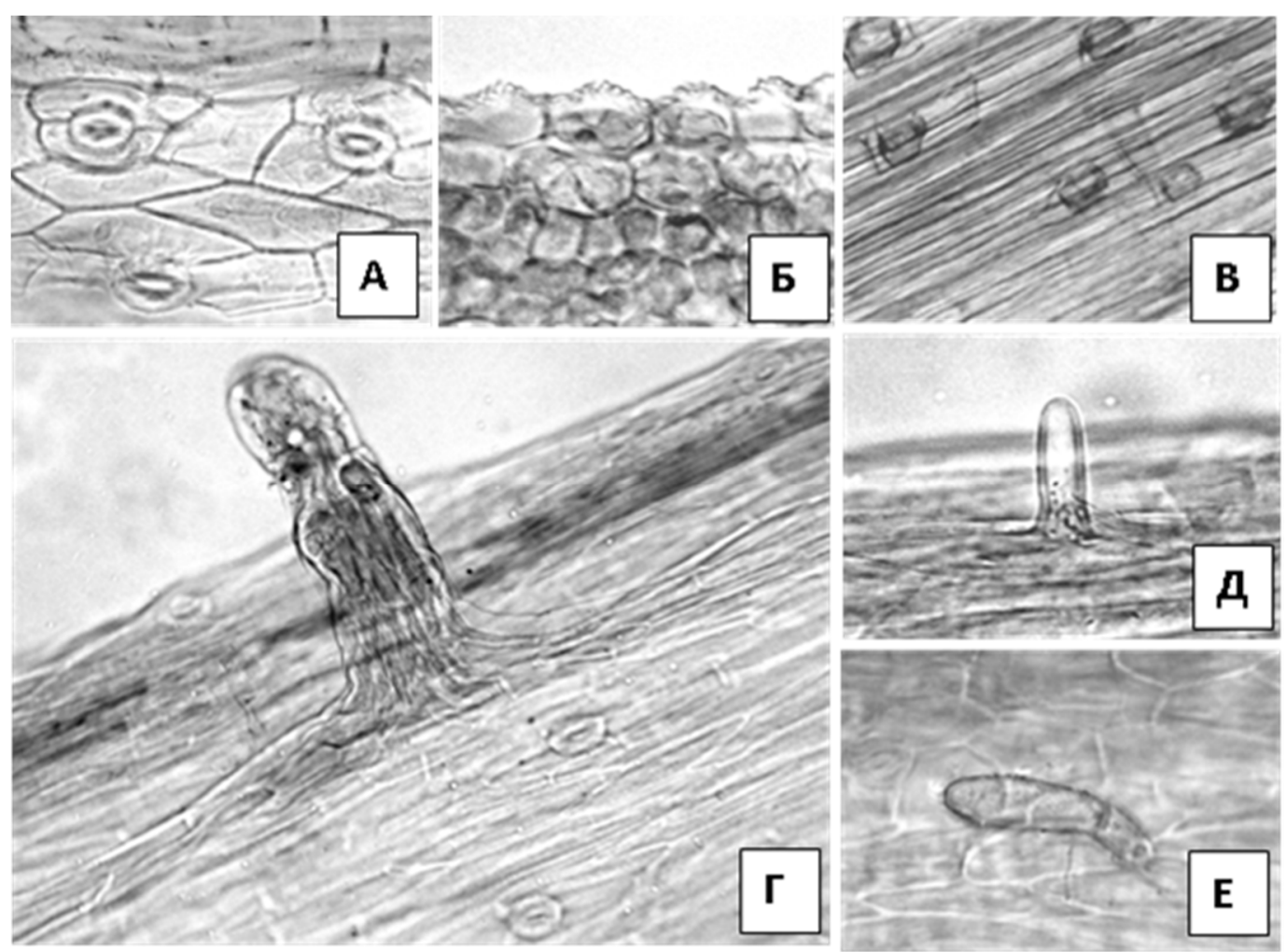

Рис. 2. Фрагменты эпидермиса стебля (Ув. 10×20, 10×40).

А - клетки эпидермиса с устьицами аномоцитного типа, Б - складчатость кутикулы, В - кристаллы оксалата кальция вдоль жилок, Г - крупный головчатый волосок с многоклеточной ножкой и многоклеточной головкой, Д - одноклеточный простой волосок, Е - головчатый волосок с 1-клеточной ножкой и 1-клеточной головкой.
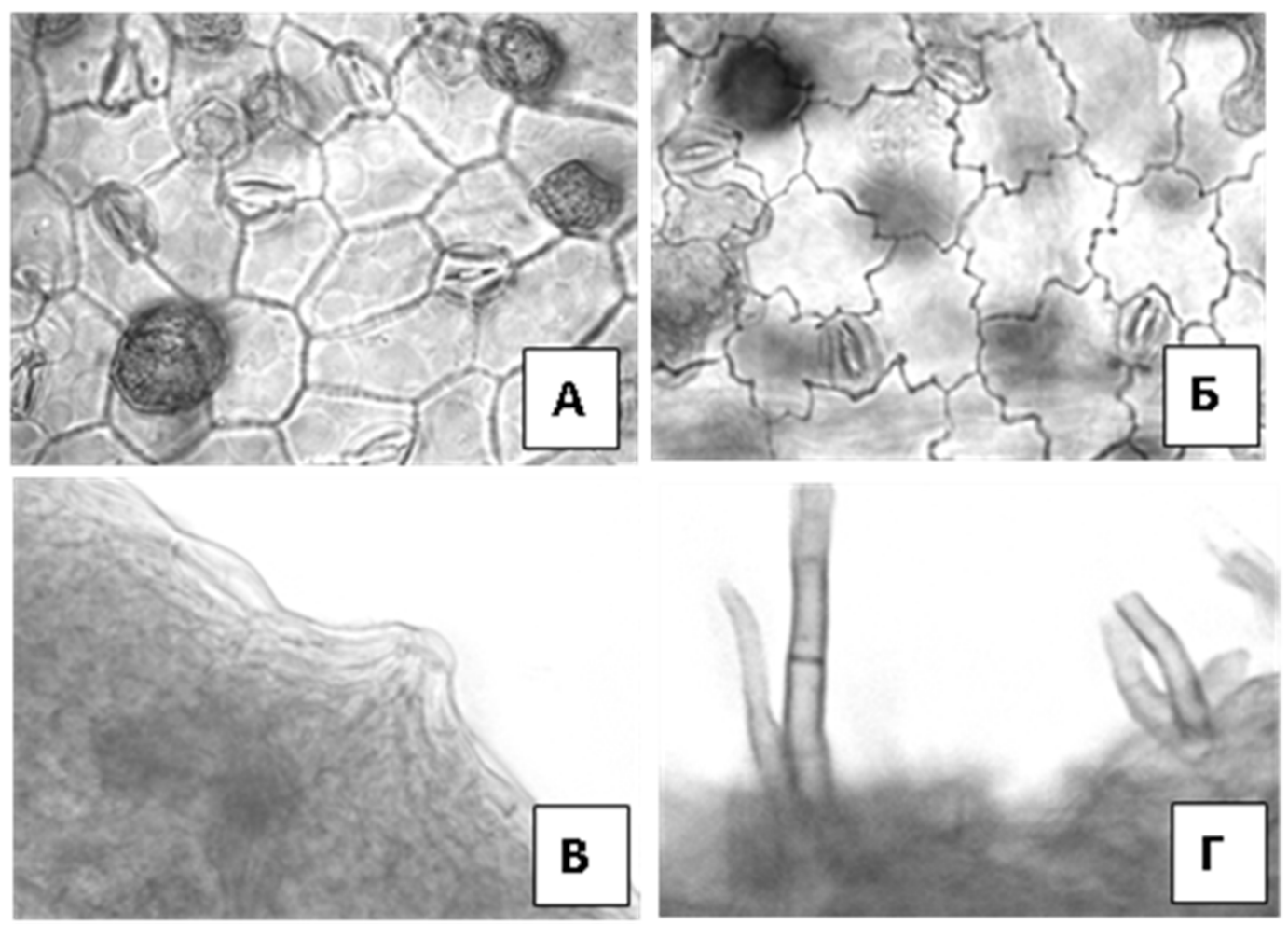

Рис. 3. Фрагменты эпидермиса листа (Ув. 10×20, 10×40).

А, Б - клетки верхнего (А) и нижнего (Б) эпидермиса с четковидными утолщениями, устьица аномоцитного типа и вместилища, В - складчатость кутикулы, Г - простые толстостенные многоклеточные волоски. 


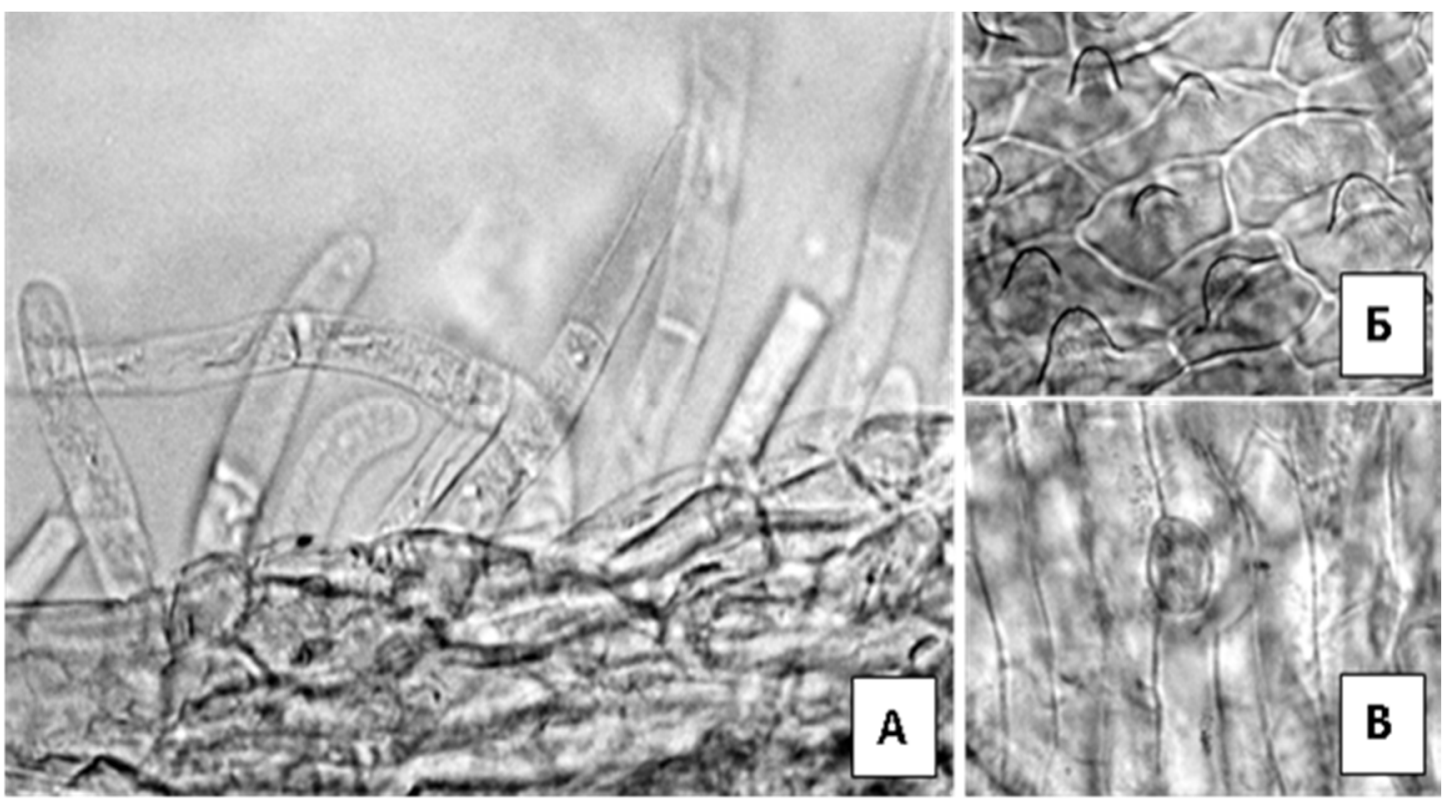

Рис. 4. Фрагменты эпидермиса чашелистика (Ув. 10×40).

А - простые тонкостенные многоклеточные волоски, Б - клетки верхнего эпидермиса с сосочковидными выростами, В - клетки нижнего эпидермиса с устьицами аномоцитного типа.
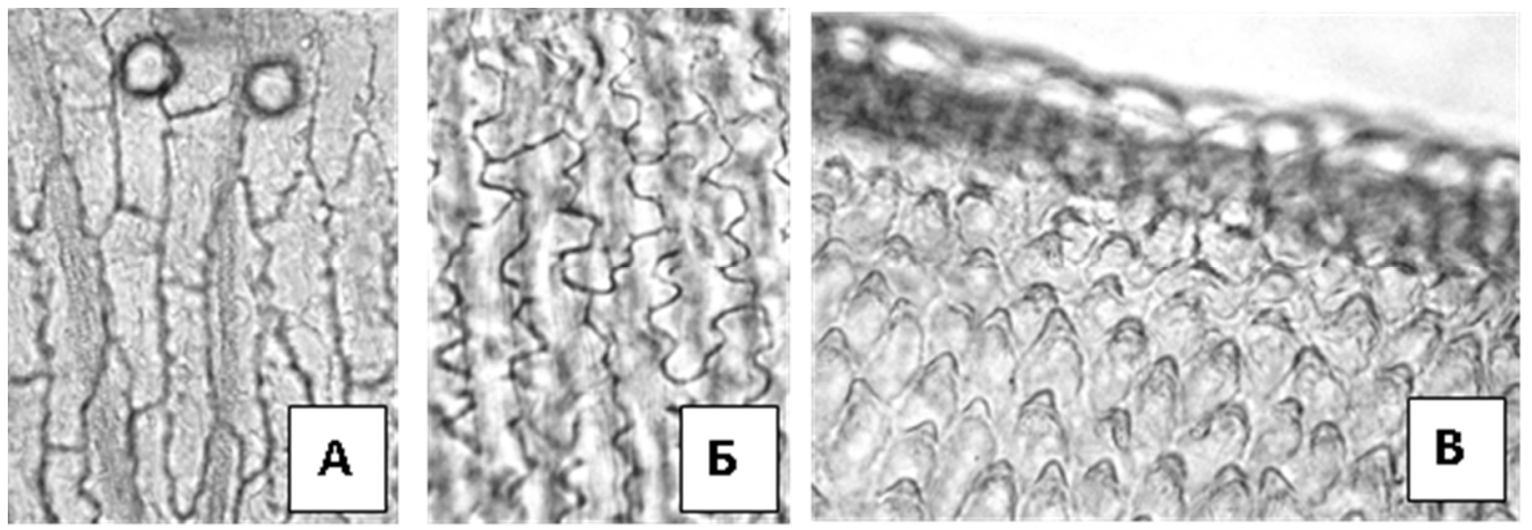

Рис. 5. Фрагменты лепестка венчика и пыльцевые зерна (Ув. 10×20, 10×40).

А - клетки верхнего эпидермиса и пыльцевые зерна, Б - клетки нижнего эпидермиса, В - сосочковидные выросты.

Клетки эпидермиса стебля вытянутые, многоугольные, с устьицами аномоцитного типа (рис. 2 А) и хорошо выраженной складчатостью кутикулы (рис. 2Б). На эпидермисе стебля имеются простые и головчатые волоски. Простые волоски 1-клеточные, толстостенные с гладкой поверхностью (рис. 2Д). Головчатые волоски 2-х типов: крупные с многоклеточной ножкой и многоклеточной головкой (рис. 2Г) и с 1-клеточной ножкой и 1-клеточной головкой (рис. 2Е). В местах прикрепления волоски образуют розетку. Вдоль жилок встречаются кристаллы оксалата кальция призматической формы (рис. 2B).

Лист. При рассмотрении листа с поверхности видны клетки эпидермиса, местами имеющие четковидные утолщения; клетки верхнего эпидермиса 5-7 угольные, с прямыми стенками, клетки нижнего эпидермиса извилистостенные. Устьица округлые, окружены 3-5 околоустьичными клетками (аномоцитный тип), расположены на обеих сторонах листа. Замыкающие клетки устьиц имеют почковидную форму. В мезофилле листа расположены вместилища с оранжево-коричневым содержимым (рис. 3А, ЗБ). Эпидермис листа имеет складчатость кутикулы (рис. 3В). Волоски редкие, простые, многоклеточные, толстостенные с гладкой поверхностью, расположены по краю листовой пластинки (рис. 3Г).

Чашелистик. При рассмотрении чашелистика с поверхности видны клетки верхнего и нижнего эпидермиса 5-7 угольные, со слегка извилистыми стенками (рис. 4Б, 4В); клетки верхнего эпидермиса имеют сосочковидные выросты (рис. 4Б). Устьица аномоцитного типа расположены на нижнем эпидермисе (рис. 4В). Волоски простые многочисленные, расположены по краю чашелис- 
тика, многоклеточные, часто перекрученные, тонкостенные с гладкой поверхностью (рис. 4А).

Лепесток венчика. Диагностическое значение для лепестка венчика имеют: клетки эпидермиса у основания с вытянутыми стенками (клетки верхнего эпидермиса со слегка извилистыми стенками, нижнего эпидермиса - более извилистостенные) (рис. 5А, 5Б), у верхушки и по краю - с сосочковидными выростами (рис. 5В). Встречается пыльца в виде крупных зерен шаровидной формы с гладкой поверхностью (рис. 5А).

Таким образом, при изучении вязеля разноцветного выявлены морфологические и анатомические признаки, характерные для представителей семейства бобовые, что согласуется с литературными данными $[13,14]$, а также установлены его отличительные особенности, имеющие диагностическое значение и позволяющие устанавливать подлинность лекарственного растительного сырья.

Результаты проведенного исследования могут быть использованы при разработке нормативной документации на новый перспективный вид отечественного лекарственного растительного сырья, содержащий комплекс биологически активных веществ, что в условиях импортозамещения позволит расширить сырьевую базу для получения доступных фитопрепаратов с разносторонней фармакологической активностью. Морфолого-анатомическое изучение вязеля разноцветного с выявлением совокупности диагностических признаков проведено впервые.

На основании проведенных исследований можно сделать следующие выводы:

1. Проведено морфологическое и анатомическое изучение травы вязеля разноцветного.

2. Впервые выявлена совокупность макро- и микродиагностических признаков, которые могут быть использованы для определения подлинности лекарственного растительного сырья.

\section{ЛИТЕРАТУРА}

1. Бубенчикова В.Н., Дроздова И.Л. Изучение состава фенольных соединений донника лекарственного методом ВЭЖХ // Химико-фармацевтический журнал. - 2004. - Т. 38, № 4. - С. 24-25.

2. Василенко Е.А., Попова О.И., Елисеева Л.М. Морфолого-анатомическое изучение травы будры плющевидной (Glechoma hederaceae L.) // Курский научно-практический вестник «Человек и его здоровье». - 2013. - № 3. - С. 96-101.
3. Великанова Н.А., Гапонов С.П., Сливкин А.И. Изучение микроскопических особенностей травы горца птичьего, собранной в городе Воронеже и его окрестностях // Вестник Воронежского государственного университета. Серия: Химия. Биология. Фармация. - 2013. - № 1. - С. 86-91.

4. Государственная фармакопея Российской Федерации XIII издания. - М. : МЗ РФ, 2016. [Электронное издание]. Режим доступа: http://pharmacopoeia.ru/gosudarstvennayafarmakopeya-xiii-online-gf-13-online, свободный (12.01.2017)

5. Дроздова И.Л. Выделение и химическое изучение полисахаридов травы донника рослого (Melilotus altissimus Thuill.) // Вестник Воронежского государственного университета. Серия: Химия. Биология. Фармация. - 2004. - № 1. - С. 173-175.

6. Дроздова И.Л., Бубенчиков Р.А. Аминокислоты фиалки полевой и донника рослого // Фармация. 2003. - № 5. - С. 14-15.

7. Дроздова И.Л., Лупилина Т.И. Морфологоанатомическое изучение травы икотника серого (Berteroa incana (L.) DC.) // Курский научнопрактический вестник «Человек и его здоровье». 2014. - № 2. - С. 94-98.

8. Иллюстрированный определитель растений Средней России. Том 2: Покрытосеменные (двудольные: раздельнолепестные) / И.А. Губанов, К.В. Киселева, В.С. Новиков, В.Н. Тихомиров. Ин-т технологических исследований. - М. : Товарищество научных изданий КМК. - 2003.665 c.

9. Кахерская Ю.С., Горячкина Е.Г., Федосеева Г.М. Сравнительная морфолого-анатомическая характеристика сырья ортилии однобокой и грушанки круглолистной // Сибирский медицинский журнал (Иркутск). - 2008. - Т. 76. № 1. - C. 84-86.

10. Киселева К.В., Майоров С.Р., Новиков В.С. Флора средней полосы России. - М.: ЗАО «Фитон+», 2010. -544 c.

11. Ковалева Л.Г., Сампиев А.М., Никифорова Е.Б., Хочава М.Р. Изучение анатомического строения плодов софоры японской // Фундаментальные исследования. - 2013. - № 6-3. - С. 651-655.

12. Растительные ресурсы СССР: Цветковые растения, их химический состав, использование; Семейства Hydrangeaceae-Haloragaceae. - Л.: Наука, 1987. $326 \mathrm{c}$.

13. Самылина И.А., Аносова О.Г. Фармакогнозия. Атлас: в 2- томах. - М.: ГЭОТАР-Медиа, 2007. T. $1 .-192 \mathrm{c}$.

14. Трембаля Я.С., Прокошева Л.И., Лапина Е.С. Анатомическое строение вегетативных органов астрагала нутового (Astragalus cicer L.) // Фармация и фармакология. - 2014. - № 6 (7). C. 33-35. 